deaths from infection (Table 3 ) be classified as inexplicable. Thus by the definition of Stanton and Oakley, ${ }^{3}$ among the 837 sudden postneonatal deaths in this series, 739 would be cot deaths of which only $62 \%$ were histologically unexplained.

Fear of cot death haunts many young parents. Inflated numbers of cot deaths do not ease their anxiety. Misdiagnosis also hinders attempts to understand aetiological mechanisms. Published reports on the sudden infant death syndrome are confused by variations in definition. Meningococcaemia and leukaemia may both present with purpura but this does not mean that they share a common aetiology, and considering them as the same can only confuse.

This work was assisted by a grant from West Midlands Regional Health Authority (locally organised research). I am grateful to the Registrar General, Shefficld Area Health Authority. Sheffield's pathologists and the Sheffield Coroner for allowing access to their records. Professor J L Emery. Dr R J Carpenter, and A Gardner gave much time in discussion.

\section{References}

1 Wedgewood RJ, Benditt EP. Sudden death in infants. Proceedings of the conference on causes of sudden death in infants, Seattle, Washington. Public Service Publication No 1412, Bethesda, Maryland: National Institute of Child Health and Human Development, 1964.

2 Pharoah POD, Morris JM. Postneonatal mortality. Epidemiol Rev 1979:1:170-83.

3 Stanton AN. Oakley JR. Pattern of illness before cot deaths. Arch Dis Child 1983:58:878-81.

4 Sunderland R. Sunderland EP. Invalid certification of young deaths. Arch Dis Child 1983:58:867-71.

5 Emery JL. The necropsy and cot death. Br Med J 1983;287: $77-8$.

${ }^{6}$ Peterson DR. Evolution of the epidemiology of sudden infant death syndrome. Epidemiol Rev 1980;2:97-112.

${ }^{7}$ Emery JL. Unexpected death in infancy. In: Hull D, ed. Recent advances in paediatrics No 5. Edinburgh: Churchill Livingstone, 1976.

${ }^{*}$ Werne J. Postmortem evidence of acute infection in unexpected death in infancy. Am J Pathol 1942;18:759-61.

9 Simpson K. Pathology of sudden death. Lancet 1947;ii:745-7.

Correspondence to Dr R Sunderland, Selly Oak Hospital, Birmingham B29 6JD.

Received 31 October 1984

\title{
Successful treatment of fetal atrial flutter and congestive heart failure
}

\author{
K HIRATA, H KATO, F YOSHIOKA, AND T MATSUNAGA \\ Departments of Pediatrics and Obstetrics, Kurume University School of Medicine, Japan
}

SUMMARY Fetal supraventricular tachycardia may cause congestive heart failure, hydrops fetalis, and intrauterine death. Tachycardia in a fetus of 34 weeks' gestation was diagnosed as atrial flutter by echocardiography, and was successfully treated by giving the mother digoxin.

Since visualisation of the fetal heart by echocardiography has become available, prenatal diagnosis of congenital cardiac anomalies and fetal arrhythmia has been possible. ${ }^{1-3}$ We have evaluated the structure of the fetal heart and the great vessels by two dimensional echocardiography, and diagnosed arrhythmia by simultaneously recording the motion of the atrial wall and the ventricular wall of the fetal heart by $\mathbf{M}$ mode echocardiography. Certain fetal arrhythmias such as supraventricular tachycardia or A-V block have clinical importance, since they may be the cause of congestive heart failure and evaluation and treatment of these conditions are, therefore, necessary.

\section{Case report}

The mother, a 28 year old gravida 1 , para 0 , had an uneventful pregnancy until week 34 of gestation when she complained of abdominal pain and was referred to Kurume University Hospital. Fetal echocardiography was carried out and showed an atrial rate of 460 beats/minute and a ventricular rate of 230 beats/minute, without any structural anomalies of the heart (Fig. 1). Atrial flutter was diagnosed. Digoxin $(0.5 \mathrm{mg})$ was given to the mother and further doses of $0.5 \mathrm{mg}$ and $0.25 \mathrm{mg}$ were administered three and 12 hours later. The fetal heart rate was continuously monitored during this time and repeated electrocardiograms were made. Five hours after the third dose of digoxin, the fetal heart rate dropped from 230 to 135 beats/minute: at that time the digoxin concentration in maternal venous blood was $1.4 \mathrm{ng} / \mathrm{ml}$. The mother was treated by a daily oral dose of $0.25 \mathrm{mg}$ of digoxin and showed no signs of digoxin intoxication. Echocardiography, undertaken when the fetal heart rate had returned to normal showed massive pleural 

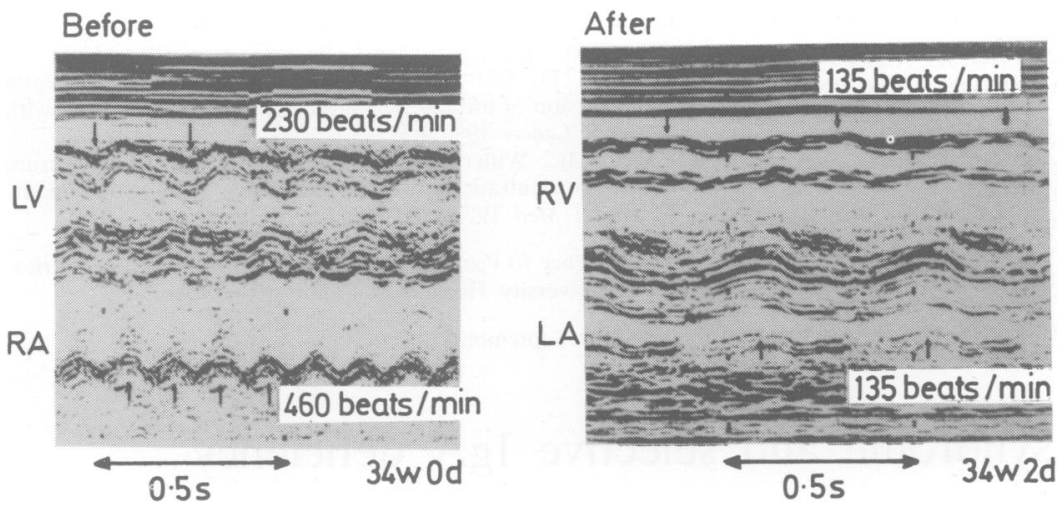

Fig. 1 Fetal $M$ mode echocardiogram before and after treatment.

RA, right atrium; RV, right ventricle; LA, left atrium; LV, left ventricle.

effusions (Fig. 2). We gave the mother an intravenous bolus injection of $20 \mathrm{mg}$ of furosemide but there was no improvement. Since the maternal membranes had ruptured caesarean section was performed (after confirming a positive shake test). The boy weighed $2300 \mathrm{~g}$ at birth, his Apgar score at one minute was 8 , and the heart rate was 150 beats/minute. He had severe respiratory distress and showed respiratory acidosis $\left(\mathrm{pH} \mathrm{7.14}, \mathrm{Po}_{2} 45 \mathrm{~mm}\right.$ $\mathrm{Hg}, \mathrm{PCO}_{2} 78 \mathrm{~mm} \mathrm{Hg}$, base excess -5 ). The direct Coombs's test and C-reactive protein were negative. The chest radiograph on day 1 showed massive pleural effusions, which had resolved by day 3 . He had transient hypocalcaemia (calcium $1.7 \mathrm{mmol} / \mathrm{l}$ $(6.7 \mathrm{mg} / 100 \mathrm{ml})$ at age 1 day, but no symptoms of

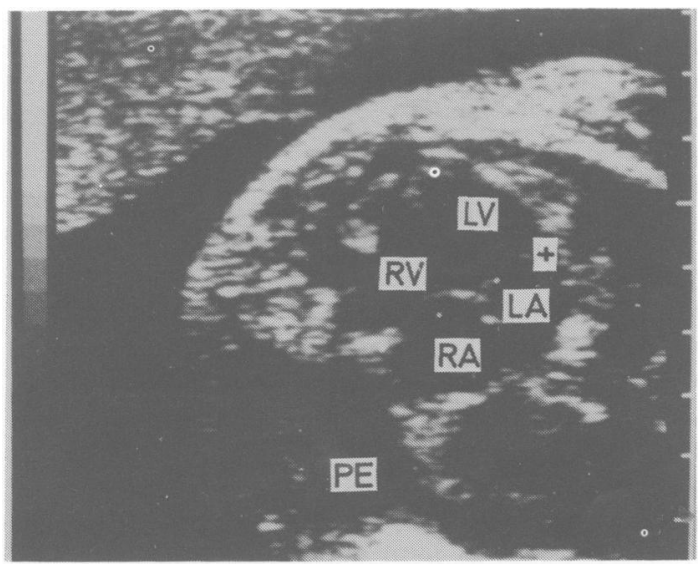

Fig. 2 Two dimensional echocardiogram of the fetus.

Massive pleural effusion (PE) was found but cardiac structure was normal. RA, right atrium; RV, right ventricle; $L A$, left atrium; LV, left ventricle. this. Digoxin concentrations in the amniotic fluid and the umbilical venous blood were $0.7 \mathrm{ng} / \mathrm{ml}$ and $0.6 \mathrm{ng} / \mathrm{ml}$ respectively. An electrocardiogram at 1 day of age showed sinus rhythm. No heart murmur was detected and no congenital heart disease was found by routine cardiac examinations, including echocardiography. He has now been treated with digitalis for seven months, has remained well, and has not suffered tachycardia or heart failure.

\section{Discussion}

As fetal dysrhythmias are important indicators of fetal distress, which may result in stillbirth, appropriated maternal and fetal management must be carried out. In our patient, atrial flutter was diagnosed by echocardiography and treatment, by administration of digoxin to the mother, was successful. There have been several reports on the transplacental treatment of fetal supraventricular tachycardia or atrial flutter, ${ }^{3-5}$ and digoxin, which reaches the fetus through the placenta, may be given to a pregnant woman with relative safety. ${ }^{6}$

We recommend the following management in cases of fetal dysrhythmia. Firstly, once fetal arrhythmia is detected by an obstetrician, echocardiography should be performed to determine the type of arrhythmia. If tachyarrhythmia such as atrial flutter or supraventricular tachycardia is found maternal digoxin administration should be considered. If any sign of fetal congestive heart failure such as ascites, pleural effusions, or hydrops fetalis develops, caesarean section or medical management by digoxin and diuretics such as furosemide should be considered, depending upon clinical evaluation of the maturation of the fetal lung. 
References

1 Allen LD, Tynan M, Cambell S, Wilkinson JL, Anderson RH. Echocardiographic and anatomical correlates in the fetus. $\mathrm{Br}$ Heart $J$ 1980;44:441-51.

2 Sahn DJ, Lange LW, Allen HD, et al. Quantitative real-time cross-sectional echocardiography in the developing normal fetus and newborn. Circulation 1980;62:588-97.

${ }^{3}$ Kleinman CS, Donnerstein RL, Yaffe CC, et al. Fetal echocardiography-a tool for evaluation of utero cardiac arrhythmias and monitoring of in utero therapy: analysis of 71 patients. $\mathrm{Am}$ J Cardiol 1983;51:237-43.

${ }^{4}$ Klein AM, Holzman IR, Austin EM. Fetal tachycardia prior to the development of hydrops-attempted pharmacologic cardioversion: case report. Am J Obstet Gynecol 1979;134:347-8.

${ }^{5}$ Kerenyi TD, Gleicher N, Meller J, et al. Transplacental cardioversion of intrauterine supraventricular tachycardia with digitalis. Lancet 1980;ii:393-5.

${ }^{6}$ Rogers MC, Willerson JT, Goldblatt A, Smith TW. Serum digoxin concentrations in the human fetus, neonate and infant $N$ Engl J Med 1972;287:1010-3.

Correspondence to Professor H Kato, Department of Paediatrics, Kurume University Hospital, Kurume 830, Japan.

Received 24 September 1984

\title{
Henoch-Schönlein syndrome and selective IgA deficiency
}

\author{
A MARTINI, A RAVELli, L D NOTARANGELO, V L BURGIO, AND A PLEBANI \\ Department of Paediatrics and Department of Internal Medicine, University of Pavia, Italy
}

SUMmaRY A 9 year old girl presented with clinical manifestations of Henoch-Schönlein syndrome and macroscopic haematuria. Laboratory investigations showed selective $\operatorname{IgA}$ deficiency and renal biopsy showed mesangial proliferative glomerulonephritis with diffuse granular deposits of $\mathrm{C} 3$ on immunofluorescence. IgA deposits were absent.

It is well documented that patients with $\operatorname{IgA}$ deficiency have an increased incidence of immune mediated diseases. ${ }^{1}$ As far as we know, however, an association between selective IgA deficiency and the clinical picture of Henoch-Schönlein syndrome has not been previously reported. This is understandable since the syndrome is believed to be caused by deposition of IgA-containing immune complexes. ${ }^{2}$ We describe an unusual case of a girl with selective IgA deficiency who presented with clinical features closely resembling Henoch-Schönlein syndrome which we believe represented an unusual variant of acute post-streptococcal glomerulonephritis.

\section{Case report}

In April 1983 a 9 year old girl presented with a mildly sore throat and low grade fever of three days' duration. One week later she had a transient erythematous rash on her face, buttocks, and legs and polyarthritis affecting the ankles, knees, and wrists; the joints were swollen, hot, and red. Over the next few days she developed diffuse colicky abdominal pain, a petechial rash on the legs, and macrohaematuria and was admitted to hospital. She was not feverish on admission and her blood pressure was $115 / 70 \mathrm{~mm} \mathrm{Hg}$. Family and personal history were unremarkable; in particular there was no history of recurrent respiratory or other infections. Physical examination showed crops of nonpruritic rust coloured macules/papules and purpuric petechiae on the ankles and calves. There was diffuse abdominal tenderness. Joint examination was normal. Laboratory investigations were as follows: haemoglobin $11 \mathrm{~g} / \mathrm{dl}$, white cells $24.5 \times 10^{9} / 1$ with $82 \%$ neutrophils, erythrocyte sedimentation rate $63 \mathrm{~mm}$ in the first hour, serum creatinine 70.7 $\mu \mathrm{mol} / \mathrm{l}(0.8 \mathrm{mg} / 100 \mathrm{ml})$, creatinine clearance 88 $\mathrm{ml} / \mathrm{minute} / 1.73 \mathrm{~m}^{2}$, albumin $2.6 \mathrm{~g} / \mathrm{dl}$. Urine analysis showed 30 to 40 red cells per high power field and slight proteinuria $(0.4 \mathrm{~g} / 24$ hours); the antistreptolysin 0 titre was positive at $1 / 1600 ; \mathrm{C} 3, \mathrm{C} 4$, and $\mathrm{CH} 50$ values were normal. Serum IgG was $2297 \mathrm{mg} / \mathrm{dl}$, IgM $237 \mathrm{mg} / \mathrm{dl}$, while IgA was repeatedly undetectable in serum, saliva, and nasal secretions (serum IgA less than $5 \mathrm{mg} / \mathrm{dl}$, secretory IgA less than 0.5 $\mathrm{mg} / \mathrm{dl}$ ). Determination of IgG subclasses by monoclonal antibodies (kindly provided by Dr Jefferies, Birmingham) failed to show any IgG subclass deficiency: cell mediated immunity, determined by $E$ rosette formation and in vitro mitogen responsiveness, was normal. Rheumatoid factor, hepatitis B antigen, and circulating cryoglobulins were absent, while antinuclear antibodies and anti-double strand DNA antibodies were positive in low titres. Skin biopsy showed a leucocytoclastic vasculitis with vascular deposition of $\mathrm{C} 3$ and fibrinogen; $\mathrm{IgA}, \mathrm{IgG}$, and IgM were absent. Percutaneous renal biopsy showed segmental and focal proliferation of mesangial cells. On immunofluorescence, diffuse granular deposits of $\mathrm{C} 3$ and faint deposits of IgG with the same pattern were present, while $\operatorname{IgA}$ and IgM were absent.

The child was given no medication except a course 